\title{
Ambiente e espacialidade social: construtividade sob a crítica da função ser humano e natureza no enfrentamento da questão ambiental
}

Funcionalidade dentro do contexto socioespacial é uma relação perceptiva e fortalecida por ações de constância de proposições, que com base numa compreensão é possível entender que o processo da espacialidade mundial é atrelado a intervenção do homem na natureza. A partir de pesquisas bibliográficas sobre o tema foi desenvolvida uma pesquisa de cunho exploratório e de natureza investigativa com o objetivo de entender a relação entre o homem e o meio ambiente. Através de processos intervencionistas de diversas matrizes de concordância e função; um tema relevante e necessário para o cumprimento de discussão dentro da filosofia clássica e moderna, a fim de entender o processo de imersão emergente dos acontecimentos dos últimos anos. Nas discussões sociais, apresenta-se como alternativa ideológica de gerar uma transformação da perspectiva na relação homem/natureza, dentro do direcionamento de como a formação da identidade do sujeito é capaz de um ser um 'além' integrativo de vivência comum e passa a mover-se sob o olhar da disciplina e da ação de respeito e conformidades com a integralização do poder que o humano carrega através de seu processo de respeito, elaboração e função de sustentabilidade macro mundial, no sentido humano através da identificação da relação meio ambiente e para demais questionamentos sobre o enfrentamento na perspectiva da condução de pensamento.

\section{Environment and social spaciality: constructivity under the criticism of human function and nature in the framework of the environmental issue}

\begin{abstract}
Functionality within the socio-spatial context is a perceptive relationship strengthened by actions of constancy of propositions, which based on an understanding, it is possible to understand that the process of world spatiality is linked to the intervention of man in nature. From bibliographical research on the subject, an exploratory and investigative research was developed in order to understand the relationship between man and the environment. Through interventionist processes of various matrices of agreement and function; a relevant and necessary theme for the fulfillment of discussion within the classical and modern philosophy, in order to understand the emergent immersion process of the events of the last years. In social discussions, it is presented as an ideological alternative to generate a transformation of perspective in the relationship between man and nature, within the direction of how the formation of the subject's identity is capable of being an integrative 'beyond' of common experience and starts to move. from the perspective of discipline and the action of respect and conformity to the integration of the power that the human carries through its process of respect, elaboration and function of global macro sustainability, in the human sense through the identification of the relation environment and for other questions about coping from the perspective of thought conduction.
\end{abstract}

Keywords: Spatiality; Environment; Philosophy.

Topic: Antropologia Social

Reviewed anonymously in the process of blind peer
Received: 11/06/2019

Approved: 14/08/2019
Tayronne de Almeida Rodrigues (iD)

Faculdade de Juazeiro do Norte, Brasil

http://lattes.cnpq.br/8602100500602426

http://orcid.org/0000-0001-9378-1456

tayronnealmeid@gmail.com

João Leandro Neto (iD

Faculdade Entre Rios do Piauí, Brasil

http://lattes.cnpq.br/0489242460344918

http://orcid.org/0000-0003-1738-1164

joaoleandro@gmail.com

Aluísio Vasconcelos de Carvalho (iD

Faculdade Guaraí, Brasil

http://lattes.cnpq.br/5200758055263996

http://orcid.org/0000-0002-3793-3133

aluisiovasconcelos@gmail.com
Referencing this:

RODRIGUES, T. A.; LEANDRO NETO, J.; CARVALHO, A. V.. Ambiente e espacialidade social: construtividade sob a crítica da função ser humano e natureza no enfrentamento da questão ambiental. Nature and Conservation, v.12, n.2, p.96-103, 2019. DOI: http://doi.org/10.6008/CBPC2318-2881.2019.001.0010

DOI: 10.6008/CBPC2318-2881.2019.002.0010 


\section{INTRODUÇÃO}

Com o passar do tempo, torna-se comum associar ao ser humano significativa parcela de culpa nos desastres naturais e em toda a territorialização de comportamento, muita das vezes não percebida, advém da ideia de que é a partir do desenvolvimento das tecnologias (essas diversas) e seus desdobramentos socioespaciais que os flagelos e acidentes com o ambiente ocorrem cada vez mais potencializados e frequentes.

Compreende-se que, devido ao desenvolvimento das civilizações, atribuiu-se, a esse fato, várias mazelas sociais, econômicas e políticas que as acompanham, essa última mais clara e sensível se tratando de espaço macro discursivo (Brasil) de tal modo que a degradação ambiental deixa de ser apenas um problema relativo à natureza e ganha a dimensão de um problema socioambiental. Leff (2007) ressalta que os problemas ambientais são advindos da civilização que, em meio à crise, utiliza de maneira exacerbada os recursos naturais, energéticos e alimentar, muitas vezes, no antagonismo da racionalização econômica e tecnológica dominante do século atual.

De acordo com Carvalho (2015) e Leff (2007), destaca-se ainda a necessidade de se buscar novos valores e conhecimentos que visem ao estabelecimento de processos de gestão dos recursos naturais que suplantem o modo capitalista de racionalidade produtiva, essa não funcionalista, em se tratando de aplicabilidade social para diversas situações percebidas, vinculados as relações intrínsecas entre sociedade e natureza e estratégias que permitam a construção do uso dos recursos sob a ótica da sustentabilidade ambiental e equidade social (MAIMON, 1996).

É imprescindível que se compreendam as questões ambientais como um meio necessário ao aceitar que a natureza, ao contrário do que se pensa ou mesmo se traduz aos diversos olhares antropocêntricos, não foi criada apenas para a espécie humana. Lenoble (1969) traduz a sua fala ao afirmar que o homem é apenas uma peça dentre as milhões de outras espécies existentes na terra, sua intelectualidade não tem valor significativo para a natureza, nem mesmo tem preferência por nenhuma vida terrestre que ela produziu.

Percebe-se que a discussão acerca da espacialidade tem contribuído de forma massiva a relação direta entre sociedade e natureza em uma ampla perspectiva sociológica e filosófica, embora não demonstre a ligação entre disciplinas como a geografia e filosofia, a intensificação do debate ambiental e o amplo domínio de expressões como sustentabilidade no vocabulário governamental, corporativo e midiático tem levado à incorporação dessa temática tanto nos fóruns da sociedade civil quanto nos mais diversos embates acadêmicos (MACHADO, 2015), destacando, assim, o objetivo primordial desta pesquisa que, a partir do levantamento bibliográfico apresenta os vários caminhos possíveis no estudo da relação entre a natureza, o homem e o espaço, os enfrentamentos e consequências de suas ações de intervenção no meio ambiente.

Por conseguinte, tais conceitos em sua variedade ocasionam prováveis confusões dada a variedade de palavras-chave (ecologia, meio ambiente, natureza, cultura, território, dentre outros), o que muitas vezes pode conduzir à banalização de conceitos que só tem a servir às abordagens do mainstream. Recai-se, sem 
salvo conduto, numa teia de tensões que são a manifestação dessas contradições que estruturam a nossa sociedade. Todavia, tais tensões se expressam concretamente a partir de seu referencial espacial e são, desse modo, lidas como tensões espaciais, resultados das práticas espaciais da sociedade em seu afortunado destino de coabitar, de conviver. Compreende-se, portanto, que estudar as tensões espaciais que dão vida às nossas distintas espacialidades é um recurso importante, senão capital, para o entendimento da realidade a partir do espaço enquanto totalidade (KOSIK, 1976).

Tomar o espaço nesses termos é reconhecer nele um conteúdo socio ecológico a partir da função filosófica de questionamento, o que significa não o reduzir a um vazio-abstrato, que se estrutura em níveis diversos da realidade, o que nos leva à compreensão da escala tanto na sua importância epistemológica quanto política; e fundamenta-se na dialética da localização-distribuição (parte-todo) dos grupos humanos em suas respectivas práticas espaciais, conduzindo esses de maneira satisfatória numa idealização de comportamento territorial. Compreendendo dessa maneira que o espaço é, enquanto produto da práxis, uma totalidade em processo permanente de resolução, um devir, que torna o tempo empírico o tempo de modo que só seja possível falarmos, quando nos referirmos ao espaço do homem, de espaço-temporalidades (SANTOS, 2002).

De acordo com Brito (2009), “As determinações naturais, portanto, no desenvolvimento do ser social perdem cada vez mais a primazia para as especificidades sociais, mas ela nunca é anulada, nunca deixa de estar presente na formação do ser social". Tal fato não significa que a humanidade em sua total origem é determinada pelo supremo existencialismo nas atividades desenvolvias no ambiente. Já no início da civilização, são encontradas determinações sociais nas relações humanas que se misturavam com as especificidades naturais.

\section{METODOLOGIA}

As informações foram obtidas a partir de pesquisas bibliográficas sobre o tema, de cunho exploratório e de natureza investigativa. Segundo Gil (2011), a pesquisa é feita mediante conhecimentos acessíveis com a execução de métodos e técnicas de investigação. Fonseca (2002) afirma que "a pesquisa bibliográfica é feita a partir do levantamento de referências teóricas já analisadas, e publicadas por meios escritos e eletrônicos, como livros, artigos científicos, páginas de web sites".

\section{DISCUSSÃO TEÓRICA}

\section{(Re)construção sócio perceptiva da relação homem/natureza através do caos funcional e diagnosticado}

A discussão da construção do espaço, numa dialética de produção e organização, há de levar em consideração a natureza, já que, segundo Moreira (2012), seria o espaço a mediação do metabolismo sociedade/natureza, animado pelo trabalho humano. Não em vão que Smith (1988), em seu Desenvolvimento Desigual, para falar da produção do espaço trata antes da produção da natureza, que Santos (1996), apoiado em Whitehead, se refere à diversificação da natureza; e que Lefebvre (2008) fala de 
uma produção/reprodução da natureza para frisar o papel do espaço na reprodução das relações sociais de produção.

Essa perspectiva que traz a natureza para o centro do debate tem seu eixo no modo marxiano de tratar a relação sociedade/natureza que pode ser percebida em diversos vieses. Isto é possível a partir do recurso ao materialismo histórico e geográfico, que credita à natureza uma historicidade. Ela é, portanto, um contraponto à visão teológica de imutabilidade das espécies e de escala da natureza (hierarquia entre animais, homens e anjos) sustentada pela visão aristotélica, e assumida pela filosofia escolástica, dos quatro elementos constituintes da natureza: água, fogo, terra e ar (DULLEY, 2004; NAIME et al., 2004). Permitia-se, desse modo, uma visão contaminada pelo relato bíblico que desconsiderava o homem como sujeito da história e abria margem para o catastrofismo como enredo dos problemas de natureza científica.

Se a perspectiva aristotélica de natureza estava fora de moda, também o estava o seu modo de pensar o espaço, que na Física IV compreendia-o a partir do topos, ou seja, do lugar. O espaço cartesianonewtoniano, ao contrário, é um espaço receptáculo (espaço container) onde repousam os corpos, num modo de ser abstrato, tanto do espaço quanto do corpo, realizando o artifício da quantificação e de controles, controle dos corpos pelo espaço, do trabalhador e das trocas (MOREIRA, 2012).

É, portanto, o espaço da individualidade, legitimando a propriedade privada e as demais entidades políticas circunscritas (Estados, unidades administrativas, planos urbanos), numa separação do espaço e do tempo que sustenta este espaço absoluto (HARVEY, 2009). Uma questão nasce dessa cisão. Como pode o homem compreender a natureza e, portanto, o espaço, se está deles apartado, reduzido a um corpo dentre outros sobre o espaço? Ou melhor, se espaço e tempo são considerados infinitos, absolutos e vazios de toda a matéria, como estariam eles ao alcance do nosso entendimento?.

Immanuel Kant a atende ao compreender o espaço, tal qual o tempo, como uma categoria da sensibilidade, ainda que como plano de organização do conhecimento espaço e tempo fossem considerados como categorias a priori, o tempo internalizado na subjetividade da sucessão dos fenômenos e o espaço externalizado na extensão objetiva das coisas. Se Kant minimiza o espaço-receptáculo absoluto de Newton ao conferi-lhe uma ordem espacial a partir da nossa sensibilidade, acaba por reforçar o espaço como algo já dado, reforçando assim o dualismo natureza exterior/natureza interior (mente e natureza; cultura e natureza) (SMITH, 1988).

Ao tratar do ser humano como personagem social, deve-se lembrar que ele passa a ser um membro pertencente a um grupo social que se torna mediador de sua relação com o natural. A naturalidade humana é regida pela funcionalidade social, incluindo as necessidades mais básicas como a alimentação e reprodução. Portanto essas relações passam a ser medidas por indicadores sociais.

A capacidade do homem de se perceber diante das mudanças não foi suficiente para que produzisse mecanismos compensatórios que garantissem que a vida na terra seria digna para todos, e não apenas para alguns que conseguissem acumular com mais eficiência as riquezas e os resultados da evolução, o modelo de exploração inaugurado quando o homem começou a vida sedentária e a produção de excedentes ainda 
se reproduz na atualidade, só que agora com mecanismos mais sofisticados de dominação e exclusão (CHACON, 2007).

A realidade social humana se cria como a junção de sujeito e objeto. Esse sujeito é o ser humano no seu aspecto social, visto como indivíduo aceito em suas relações reais, com os grupos, as classes, o conjunto da sociedade. O objeto é o empírico, as coisas sensíveis, os produtos, entre os quais figuram as técnicas e as ideias e as instituições. Karl Marx em sua obra 'Contribuição à crítica da economia política' fala que

A conclusão geral a que cheguei e que, uma vez adquirida, serviu de fio condutor dos meus estudos, pode formular-se resumidamente assim: na produção social da sua existência, os homens estabelecem relações determinadas, necessárias, independentes da sua vontade, relações de produção que correspondem a um determinado grau de desenvolvimento das forças produtivas materiais. O conjunto destas relações de produção constitui a estrutura econômica da sociedade, a base concreta sobre a qual se eleva uma superestrutura jurídica e política e à qual correspondem determinadas formas de consciência social. O modo de produção da vida material condiciona o desenvolvimento da vida social, política e intelectual em geral.

Levando em conta as relações estabelecidas no texto, o ser humano enquanto sujeito histórico real, que no processo social de produção e reprodução cria a base da realidade social como totalidade nas relações sociais. É também indicador de uma forma de dependência e aponta para uma direção: a estrutura econômica. Esta é a base sobre a qual se ergue o edifício da sociedade. Assim, cada modo de produção gera uma superestrutura que lhe é correspondente e que não é mais do que a expressão das relações materiais dominantes.

\section{Função Caos: Filosofia da Consciência aplicada ao fornecimento de indução a solução}

Segundo Gallo (2008), são três ordens de saberes que aprofundam e dividem o caos, trazendo consigo significados: a filosofia, que cria conceitos; a arte, que cria afetos, sensações; e a ciência, que cria conhecimentos. Cada uma possui sua significação particular e elas não podem ser confundidas, contudo há um diálogo transversal entre elas. Cada uma delas, à sua maneira, é um esforço de luta contra o caos, um na tentativa de se obter um mínimo de ordem, também pode ser considerada uma reação contra a opinião, que promete algo impossível que é a eliminação do caos. Considera-se que somente com a morte que é possível vencer o caos, pois só não há caos quando já não há nada.

Na cosmogonia egípcia o Caos é uma energia poderosa do mundo informe e não ordenado, que cinge a criação ordenada, como o oceano circula a terra. Existia antes da criação e coexiste com o mundo formal, envolvendo-o como uma imensa e inexaurível reserva de energias, nas quais se dissolverão as formas nos fins dos tempos. Na tradição chinesa, o Caos é o espaço homogêneo, anterior à divisão em quatro horizontes, que equivale à criação do mundo. Esta divisão marca a passagem ao diferenciado e a possibilidade de orientação, constituindo-se na base de toda a organização do cosmo. Estar desorientado é entrar no Caos, de onde não se pode sair, a não ser pela intervenção de um pensamento ativo, que atua energeticamente no elemento primordial.

Entre os primatas mais evoluídos, considerados superiores, com especial destaque na espécie humana, observa-se uma aptidão natural na capacidade de aprendizagem rápida, sobretudo em situações de caráter social, de progressiva flexibilização mental à medida que o comportamento deixa de depender de ações instintivas, substituindo-as por hábitos. Portanto, assume a espécie humana uma importância que a 
torna, comparada a outras espécies de animais, incapaz de sobreviver sozinha no momento que nasce, contudo em contraponto, constitui imensa capacidade de aprendizagem através da interação com o meio físico, o que a torna superior as demais. Este parece ser um fato realmente novo dentre os fenômenos universais conhecidos. Nesta esteira, surge o conceito de 'Metaconsciência' como

\begin{abstract}
Por ser reflexiva, a 'Metaconsciência', em novo conceito, é uma instância da mente humana capaz de aprender a dirigir o conhecimento e consequentemente a ação, no sentido de um desenvolvimento organizado. Sabe, em primeiro lugar, que não sabe, e aceita que pode ou não vir a saber. O desenvolvimento psíquico básico, como conhecido em psicanálise, é fundamental para este passo subsequente. 0 momento em que isto ocorre em uma pessoa é extremamente difícil de ser definido, mas pode-se imaginá-lo como uma espécie de consciência clara. Outros vértices de observação chamariam a isto de iluminação, transcendência, inspiração etc.. O sentido não é o mesmo, mas tem semelhanças, pois a psicanálise tem conseguido ir um pouco além dos limites impostos pela circunscrição restritiva de uma investigação eminentemente científica, buscando colaboração da mística, da estética, da filosofia, procurando por outro lado não cair nos processos que levam a ideologias: misticismo, filosofismo etc..
\end{abstract}

O homem, vivendo seu período de modernidade que, então se considerava um ser à parte da natureza, passa a ver sua permanência como espécie dentro de uma cosmovisão totalmente fora de contexto e se excluiu do processo natural, perfazendo uma nova relação do homem com a natureza, onde ele próprio passa a ser oponente à natureza, pois ela se torna empecilho ao seu desenvolvimento científico. A Revolução Industrial pode ser considerada um marco na história do progresso humano e na epistemologia ambiental. Ocorreu nesse período de desenvolvimento da indústria um salto de crescimento nos meios urbanos e fortalecimento da classe burguesa diante do sistema feudal em fase de decadência. Quanto mais domínio sobre os meios de produção maior o desenvolvimento social e emancipatório do homem perante o meio.

A dominação da técnica, fundamental para o triunfo da economia, exige, segundo Mueller (1996), que o homem passe a também ser subjugado, pois faz parte desta natureza. Mueller (1996) ainda complementa, dizendo que a técnica além de liberar o homem da natureza, acelerando e intensificando a satisfação das necessidades, ela gera outras, multiplicando os meios de satisfazê-las e, com isso, cria metanecessidades, isto é, necessidades a serem satisfeitas exclusivamente por uma mediação técnica cada vez mais complexa e, assim, ao infinito.

A tecnologia é necessária cada vez mais aos indivíduos, tornando a sociedade dependente, sob os aportes do positivismo, que acendia dando por pretexto o crescimento de uma ideologia que fosse dominadora fundada a luz da primeira Revolução Industrial, o capitalismo. O projeto civilizatório capitalista, arraigado pelos enfretamentos da Revolução e da ciência positivista, influencia na criação de atividades sociais por conseguir firmar e frutificar o sistema produtivo.

\title{
CONCLUSÕES
}

O processo de trabalho é, desse modo, um processo de humanização da natureza e de naturalização do homem, o que, ao tempo que sustenta uma natureza histórica e dinâmica frente a uma natureza estática e mecânica, põe a questão da produção da natureza a partir da diversidade. Desse modo, é que faz sentido 
a afirmação de Slavoj Zizek de que 'a natureza não existe', pois mais do que uma natureza histórica - e exatamente por conta disso - o que existe é uma diversidade de naturezas.

A ratificação do espaço relacional se dá pela prática efetivada pelo trabalho humano, a qual é mediada pela técnica na conformação da seletividade que elege uma localização dentre outras, todas formando o complexo de distribuições de modo que a relação de uma com outras nos permita falar de uma localização posicional. O trabalho mediado pela técnica reúne tempo e espaço na concreticidade do real, numa dinâmica espaço-temporal que sofre um permanente processo de reestruturação socioespacial.

As analogias expostas entre essas áreas do saber não são feitas de modo casual. Especificam a influência mútua entre os fenômenos da natureza e a maneira como se comportam em novas dimensões complexas. No indivíduo humano, a dimensão 'Metaconsciente' ocorre em uma categoria nunca vista anteriormente, diferenciando-se de qualquer processo conhecido: a atividade reflexiva da própria reflexão, cognominada temporariamente aqui como 'Metaconsciência'. O respaldo deste conceito em outras áreas do saber serve especificamente para clarificar a proposta, no entanto abre espaço para uma compreensão ampla da existência. Independente das percepções metafísicas próprias a tal raciocínio é um conceito eminentemente prático.

Nesta perspectiva, as considerações acima enfatizam um ponto de vista, não tão novo assim, contextualizador de várias ideias e articulador de coparticipações em diversas áreas. A 'Metaconsciência' classifica um 'estado' que se desdobra do indivíduo à sociedade, e da coletividade à universalidade: é um novo elemento constituinte da totalidade conhecida, servindo de referência para um processo consciente e organizado de desenvolvimento.

\section{REFERÊNCIAS}

BRITO, T.. Marx e Lukács: a relação sociedade e natureza. In: COLÓQUIO MARX E ENGELS, 6. Anais. Campinas: UNICAMP, 2009.

CARVALHO, A. V.. Educação ambiental no desenvolvimento sustentável municipal. Desafios, Palmas, v.2, n.1, p.97-108, 2015. DOI: https://doi.org/10.20873/uft.23593652.2015v2n1p97

CHACON, S. S.. O sertanejo e o caminho das águas: políticas públicas, modernidade e sustentabilidade no semi-árido. Fortaleza: BNB, 2007.

DESCARTES, R.. Discurso do método. São Paulo: Convívio, 2005.

DULLEY, R. D.. Noção de natureza, ambiente, meio ambiente, recursos ambientais e recursos naturais. Agricultura em São Paulo, São Paulo, v.51, n.2, p.15-26, 2004.

FONSECA, J. J. S.. Metodologia da pesquisa científica. Fortaleza: UEC, 2002.

GALLO, S.. Deleuze e a educação. São Paulo: Autêntica, 2008.
GIL, A. C.. Metodologia do ensino superior. 4 ed. São Paulo: Atlas, 2011.

JUNIOR, F. P.. Nem Caos, nem Cosmos: "Conhecimento" e "Metaconsciência" (sobre a possibilidade de uma mente humana). Ide, São Paulo, v.35, n.54, 2012.

LEFEBVRE, H.. Space, difference, everyday life. New York: Routledge, 2008.

LEFF, E.. Epistemologia ambiental. 4 ed. São Paulo: Cortez, 2007.

LEFF, E.. Saber Ambiental: Sustentabilidade, Racionalidade, Complexidade, Poder. 7 ed. Petrópolis: Vozes, 2009.

LENOBLE, R.. História da ideia de natureza. Lisboa: Edições 70, 1969.

MACHADO, T. A.. Natureza e espaço um breve ensaio sobre a espacialidade humana a partir da noção marxiana do metabolismo socioecológico. Entre-Lugar, Dourados, v.6, n.11, 2015.

MAIMON, D.. Passaporte Verde: Gestão ambiental e competitividade. Rio de Janeiro: Qualitymark, 1996. 
MARX, K.. Contribuição à crítica da economia política. São Paulo: Martins Fontes, 1977.

MONTIBELLER-FILHO, G.. O mito do desenvolvimento sustentável: meio ambiente e custos sociais no moderno sistema produtor de mercadorias. 3 ed. Florianópolis: EDUFSC, 2008.

MOREIRA, R.. O pensamento geográfico brasileiro: as matrizes clássicas originárias. São Paulo, Contexto: 2012.

MUELLER, C. C.. Economia e meio ambiente na perspectiva do mundo industrializado: uma avaliação da economia mundial neoclássica. Estudos Econômicos, São Paulo, v.26, n.2, p.261-304, 1996.
NAIME, R.; GARCIA, A. C. A.. Percepção ambiental e diretrizes para compreender a questão do meio ambiente. Novo Hamburgo: Feevale, 2004.

SANTOS, M.. Por uma geografia cidadã: por uma epistemologia da existência. Boletim Gaúcho de Geografia, Porto Alegre, v.21, p.7-14, 1996.

SEN, A.. Desenvolvimento como liberdade. São Paulo: Companhia das Letras, 2010.

SILVA, C. E.. Elaboração de TCC e publicação de artigos: for starters. Aracaju: Sustenere Publishing, 2018.

SMITH, N.. Desenvolvimento desigual: natureza, capital e produção de espaço. Rio de Janeiro: Bertrand Brasil, 1988.

A CBPC - Companhia Brasileira de Produção Científica (CNPJ: 11.221.422/0001-03) detém os direitos materiais desta publicação. Os direitos referem-se à publicação do trabalho em qualquer parte do mundo, incluindo os direitos às renovações, expansões e disseminações da contribuição, bem como outros direitos subsidiários. Todos os trabalhos publicados eletronicamente poderão posteriormente ser publicados em coletâneas impressas sob coordenação da Sustenere Publishing, da Companhia Brasileira de Produção Científica e seus parceiros autorizados. Os (as) autores (as) preservam os direitos autorais, mas não têm permissão para a publicação da contribuição em outro meio, impresso ou digital, em português ou em tradução. 